\title{
Sentinel Node Biopsy Examination for Breast Cancer in a Routine Laboratory Practice: Results of a Pilot Study
}

\author{
Joon-Joon Khoo ${ }^{*}$, Chen-Siew Ng$^{2}$, Subathra Sabaratnam ${ }^{1}$, Sarojah \\ Arulanantham ${ }^{3}$
}

\begin{abstract}
Background: Examination of sentinel lymph node (SLN) biopsies provides accurate nodal staging for breast cancer and plays a key role in patient management. Procurement of SLNs and the methods used to process specimens are equally important. Increasing the level of detail in histopathological examination of SLNs increases detection of metastatic tumours but will also increase the burden of busy laboratories and thus may not be carried out routinely. Recommendation of a reasonable standard in SLN examination is required to ensure high sensitivity of results while maintaining a manageable practice workload. Materials and Methods: Twenty-four patients with clinically node-negative breast cancer were recruited. Combined radiotracer and blue dye methods were used for identification of SLNs. The nodes were thinly sliced and embedded. Serial sectioning and immunohistochemical (IHC) staining against AE1/AE3 were performed if initial H\&E sections of the blocks were negative. Results: SLNs were successfully identified in all patients. Ten cases had nodal metastases with 7 detected in SLNs and 3 detected only in axillary nodes (false negative rate, FNR=30\%). Some 5 out of 7 metastatic lesions in the SLNs $\mathbf{( 7 1 . 4 \% )}$ ) were detected in initial sections of the thinly sliced tissue. Serial sectioning detected the remaining two cases with either micrometastases or isolated tumour cells (ITC). Conclusions: Thin slicing of tissue to 3-5mm thickness and serial sectioning improved the detection of micro and macro-metastases but the additional burden of serial sectioning gave low yield of micrometastases or ITC and may not be cost effective. IHC validation did not further increase sensitivity of detection. Therefore its use should only be limited to confirmation of suspicious lesions. False negative cases where SLNs were not involved could be due to skipped metastases to non-sentinel nodes or poor technique during procurement, resulting in missed detection of actual SLNs.
\end{abstract}

Keywords: Breast carcinoma - sentinel lymph nodes - thin-slicing - serial sectioning - immunohistochemical validation

Asian Pac J Cancer Prev, 17 (3), 1149-1155

\section{Introduction}

It is well accepted that axillary nodal status is one of the most important prognostic factors for patients with breast cancers predicting recurrence and survival (Wilking et al., 1992; Dauway et al., 1999); as well as determining subsequent adjuvant therapy. However, axillary nodal clearance carries significant morbidity (Lin et al., 1993) including lymphedema, shoulder motion restriction and paraesthesia. Proper identification of true sentinel lymph nodes (SLNs) and detailed histopathological examination predicts with a high degree of accuracy the presence or absence of metastases in the remaining axillary nodes (Giuliano et al., 1994; Turner et al., 1997; Veronesi et al., 1997; Borgstein et al., 1998; Krag et al., 1998; Cox et al., 2000). Sentinel lymph node biopsy, without the associated morbidity, (Veronesi et al., 1997; Krag et al., 1998) has thus gained popularity as an alternative to standard axillary lymph node (ALN) clearance (Giuliano et al., 1994; Giuliano et al., 1995; Albertini et al., 1996; Giuliano et al., 1997).

However, procurement and detailed assessment of SLN biopsies is fraught with potential problems and controversies (Chagpar et al., 2003; Jakub et al., 2003). Firstly, detection of sentinel nodes as the first regional lymph nodes to receive drainage from the breast is of paramount importance. It should be done in the proper manner with combined radiotracer and blue dye technique (Vijayakumar et al., 2005; Goyal et al., 2006) and procured by an experienced surgeon (Cody et al., 1999; Vijayakumar et al., 2005) to prevent missed detection of the actual SLNs.

Previous authors have reported that increasing the level of detail in histopathological examination of SLNs would improve the identification of nodal disease (Jannink et al., 1998; Cserni, 1999; Turner et al., 1999; Weaver et al., 2000; Torrenga et al., 2001; Grabau et al., 2011; Andersson et al., 2013). However, optimal tissue processing with 
cost-effective methods of histopathological examination of SLN is necessary. A modified procedure should be adapted for use in a routine practice without unnecessarily over-stretching workload and laboratory budget. However no consensus exists for a protocol that ensures a reasonable workload and cost-effect while maintaining a clinically acceptable sensitivity for detection of nodal disease (Turner et al., 1997; Snider et al., 1999; van Diest, 1999; van Diest et al., 1999; Veronesi et al., 1999).

In this study we examine the yield of SLNs assessment using a modified detailed histopathological examination in a routine laboratory practice.

\section{Materials and Methods}

This is a prospective pilot study where patients with clinically node-negative breast cancers irrespective of tumour size were recruited between the period September 2010 and December 2012 in our hospital. All patients gave verbal and written consent to the procedure.

In each patient, SLNs were identified and located using a combination of technetium radiotracer and blue dye preoperatively and operatively if necessary. The identified nodes were harvested, separately labelled and sent to the laboratory. In the same operation the patients had either wide local excision or mastectomy with simultaneous axillary clearance as originally planned irrespective of SLN status.

All SLNs obtained were fixed in $10 \%$ buffered formalin at a neutral $\mathrm{pH}$ of 7 and labelled accordingly before submitting to the laboratory for processing. Nodes under $5 \mathrm{~mm}$ in diameter were examined and processed as a whole and nodes $5-10 \mathrm{~mm}$ in diameter were halved. Nodes larger than $10 \mathrm{~mm}$ in diameter were thinly sliced into blocks of 3 to $5 \mathrm{~mm}$ thickness each and processed as individual blocks. For each individual block, one initial Haematoxylin and Eosin (H\&E) stained section was done and screened. If these sections were negative for metastasis, serial sectioning was further done sequentially for 200 microns $(0.2 \mathrm{~mm})$; equivalent to approximately 50 sequential levels. For each level except every $7^{\text {th }}$ step level, $4 \mu \mathrm{m}$-thick sections were stained with H\&E. At every 7 th step level, IHC staining for AE1/AE3 was done. Tumours larger than $0.2 \mathrm{~mm}$ but less than or equal to $2.0 \mathrm{~mm}$ were classified as micrometastases and any tumour larger than $2.0 \mathrm{~mm}$ were macrometastases. Isolated tumour cells (ITC) were defined as single or a group of tumour cells aggregating to less than $0.2 \mathrm{~mm}$.
Histopathological examination of subsequent wide local excision of the breast tumour or mastectomy with axillary node clearance was performed routinely. The results of this study were presented using descriptive statistics.

\section{Results}

Twenty four patients with clinically node-negative breast carcinomas were included in the study. Their ages ranged from 34 to 81 years with a median of 52 years. All patients but one had unifocal invasive ductal carcinomas. One patient had invasive lobular carcinoma with multifocal locations in the breast. The unifocal tumours in the remaining 23 patients were predominantly located at the upper outer quadrant $(41.7 \%)$ or upper inner quadrant (29.2\%). The size of the breast tumours ranged from 10.0 to $55.0 \mathrm{~mm}$ with a median of $27.5 \mathrm{~mm}$ in greatest diameter.

Sentinel lymph nodes were identified in all 24 patients $(100 \%)$ with combination of the radiotracer technetium and blue dye. A total of 45 sentinel nodes were harvested with an average of 1.9 sentinel nodes per patient. A further 315 non-sentinel lymph nodes were removed in the axillary basin with the excision of the tumour. The patients had between 7 to 22 non-sentinel nodes removed with a mean of 13.1 non-SLNs per patient.

Altogether, 121 paraffin blocks were made from sentinel nodes harvested, with a mean of 5.0 blocks per patient. Initial H\&E sections of the thinly sliced blocks showed tumour in 5 cases. The metastatic tumours in these 5 cases were equal or more than $2 \mathrm{~mm}$ in diameter (macrometastases). One of these 5 cases had concurrent

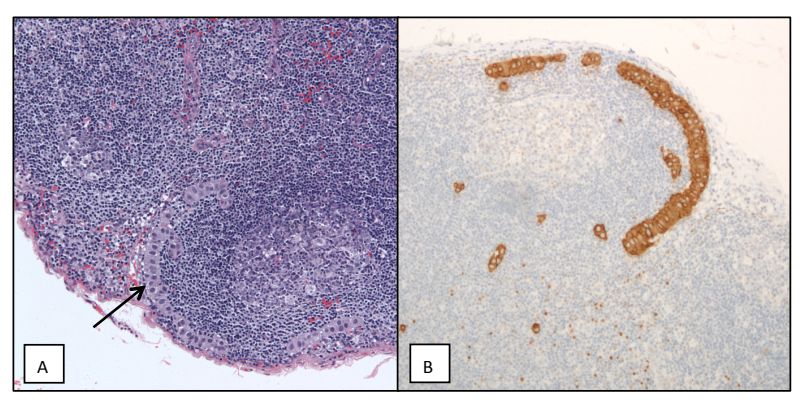

Figure 1. A: Photomicrograph of sentinel lymph node with small focus of carcinoma (isolated tumour cells) indicated with an arrow (H\&E, original magnification x100). B: shows the metastatic carcinoma in the SLN confirmed by AE1/3 stain (IHC stain with AE1/AE3, original magnification $\mathbf{x 1 0 0 )}$

Table 1. Showing the Workload to Process the Sentinel Lymph Nodes with the Resultant Outcomes

\begin{tabular}{|c|c|c|c|c|c|c|c|c|}
\hline No. of cases & Total SLNs & SLNs /case & Total Blks & Blks /case & H\&E sections & H\&E /case & No of IHC & IHC /case \\
\hline 24 & 45 & 1.9 & 121 & 5 & 121 & 5 & 0 \\
\hline \begin{tabular}{l} 
Outcome: 5 cases detected with tumour in initial H\&E sections = 5/24 (20.8\%), one of which also had non-SLN metastases. \\
All tumours in the SLNs were macrometastases \\
\hline $\begin{array}{l}19 \\
\text { (remaining) }\end{array}$
\end{tabular}$\quad 34$ & 1.8 & 93 & 4.9 & 4655 & 245 & 651 \\
\hline $\begin{array}{l}\text { Outcome: } 2 \text { cases detected with tumour in serial sectioning :one of which also had non-SLN metastases and the other had } \\
\text { isolated tumour clusters in the SLN, less than 0.2mm [pN0 (i+)] }\end{array}$ \\
\hline
\end{tabular}


Sentinel Node Biopsy Examination for Breast Cancer in a Routine Laboratory Practice: Results of a Pilot Study

axillary nodal metastases.

The remaining 19 cases or 93 blocks of SLNs had no tumour in initial H\&E sections. Subsequently, each block was serially sectioned upto 200 microns giving approximately 50 additional levels stained with $\mathrm{H} \& \mathrm{E}$ and IHC validation at every 7 th step. A total of 4655 $\mathrm{H} \& \mathrm{E}$ sections and 651 sections for IHC staining were done (Table 1). 2 cases showed metastatic tumour after serial levelling of H\&E sections. One case had a group of tumour cells, aggregating to less than $0.2 \mathrm{~mm}$. This tumour was classified as isolated tumour cells (ITC) (Figure 1A). The second case had tumour measuring $1 \mathrm{~mm}$ in diameter (micrometastases) but also had positive lymph nodes in the axillary dissection. IHC validation with AE1/AE3 antibodies (Figure 1B) confirmed the presence of both these tumours in the SLNs but did not pick up any further cases of metastases in the other remaining 17 cases.

In summary, 7 cases were found to have SLNs metastases. $5(71.4 \%)$ were found at initial H\&E sections of the thin blocks and $2(28.6 \%)$ on further serial sectioning. Our study found that if metastatic disease existed in SLNs, superficial initial section examination would miss detection in $28.6 \%$ of cases but tumour missed were either micrometastases or isolated tumour cells. No macrometastases were missed.

Altogether, 10 of our 24 cases included in this study $(41.7 \%)$ had nodal metastases. SLNs were the only site of metastases in 5 out of 10 cases $(50 \%)$. Two cases

Table 2. Showing Status of Sentinel and Axillary Lymph Nodes (non-SLNs) in Patients with Breast Carcinomas $(n=24)$

\begin{tabular}{lccc}
\hline \multicolumn{1}{c}{ Methods used to detect metastatic tumours in SLNs } & ALN - ve & ALN+ve & $\begin{array}{c}\text { Total } \\
\text { (No. of cases) }\end{array}$ \\
\hline Tumour positive in initial H\&E sections in thin blocks SLNs & 4 & 1 & 5 \\
Tumour positive in serial sectionings / IHC of SLNs & 1 & 1 & 2 \\
No tumour visualised in SLNs (in all methods used above) & 14 & $* 3$ & 17 \\
Grand Total (number of cases) & 19 & 5 & 24 \\
\hline
\end{tabular}

*SLNs = sentinel lymph nodes; ALNs = axillary lymph nodes that were non-sentinel nodes found in axillary clearance; ALNs -ve = no metastatic tumour in ALNs; ALNs +ve = metastatic tumours in ALNs; *3 = False negative cases (tumour not detected in SLNs but detected in ALNs).

Table 3. Breast Carcinoma Cases with Nodal Metastases

\begin{tabular}{|c|c|c|c|c|c|c|c|c|c|c|}
\hline Case & $\begin{array}{l}\text { 1oTumour } \\
\text { size }\end{array}$ & $\begin{array}{l}\text { No. } \\
\text { of } \\
\text { SLNs }\end{array}$ & $\begin{array}{c}\text { No. } \\
\text { of } \\
\text { blks } \\
\text { of } \\
\text { SLN }\end{array}$ & $\begin{array}{c}\text { Mets in SLN } \\
\text { :Level of sections }\end{array}$ & $\begin{array}{l}\text { Level where } \\
\text { tumour } \\
\text { found in } \\
\text { SLNs }\end{array}$ & IHC & $\begin{array}{l}\text { No. of } \\
\text { ALNs }\end{array}$ & $\begin{array}{l}\text { State of } \\
\text { ALNs } \\
\text { (Non- } \\
\text { SLNs) }\end{array}$ & $\begin{array}{l}\text { Largest } \\
\text { size of } \\
\text { Mets }\end{array}$ & $\begin{array}{c}\text { Total } \\
\text { nodes } \\
\text { involved }\end{array}$ \\
\hline 1 & $30.0 \mathrm{~mm}$ & 4 & 7 & $\begin{array}{c}\text { Initial section } \\
\text { of all } 4 \text { blks: } 2 \\
\text { SLNs+ }\end{array}$ & $1^{\mathrm{st}}$ & Not done & 12 & $\begin{array}{c}\text { All } \\
\text { Negative }\end{array}$ & $\begin{array}{l}\text { SLN: } 12.0 \\
\mathrm{~mm}\end{array}$ & $1 / 8$ \\
\hline 2 & $22.0 \mathrm{~mm}$ & 2 & 12 & $\begin{array}{c}\text { Initial section of } \\
\text { only } 2 \text { of } 12 \text { blks: } \\
1 \text { SLN+ }\end{array}$ & $1^{\mathrm{st}}$ & Not done & 11 & $\begin{array}{c}\text { All } \\
\text { Negative }\end{array}$ & $\begin{array}{l}\text { SLN: } 2.0 \\
\mathrm{~mm}\end{array}$ & $1 / 13$ \\
\hline 3 & $17.0 \mathrm{~mm}$ & 1 & 2 & $\begin{array}{l}\text { Initial section in } \\
\text { both blks: } 1 \text { SLN+ }\end{array}$ & $1^{\mathrm{st}}$ & Not done & 6 & $\begin{array}{c}\text { All } \\
\text { Negative }\end{array}$ & $\begin{array}{l}\text { SLN: } 12.0 \\
\mathrm{~mm}\end{array}$ & $1 / 7$ \\
\hline 4 & $20.0 \mathrm{~mm}$ & 2 & 2 & $\begin{array}{l}\text { Initial section in } 1 \\
\text { of blks: } 1 \text { SLN+ }\end{array}$ & $1^{\mathrm{st}}$ & Not done & 16 & $\begin{array}{c}\text { All } \\
\text { Negative }\end{array}$ & $\begin{array}{l}\text { SLN: } \\
2.0 \mathrm{~mm}\end{array}$ & $1 / 18$ \\
\hline 5 & $25.0 \mathrm{~mm}$ & 3 & 5 & $\begin{array}{l}\text { Initial section in } \\
\text { all blks: } 3 \text { SLNs+ }\end{array}$ & $1^{\mathrm{st}}$ & Not done & 16 & $\begin{array}{l}\text { Positive } \\
\text { in } 8 / 16\end{array}$ & $\begin{array}{l}\text { SLN: } 10.0 \\
\mathrm{~mm}\end{array}$ & $11 / 19$ \\
\hline 6 & $50.0 \mathrm{~mm}$ & 1 & 6 & $\begin{array}{l}\text { Serial section in } 2 \\
\text { of } 6 \text { blks: } 1 \text { SLN+ }\end{array}$ & $\begin{array}{l}\text { BlkA3: S19, } \\
\text { Blk A5: S7 }\end{array}$ & Positive & 23 & $\begin{array}{c}\text { All } \\
\text { Negative }\end{array}$ & SLN:ITC & $1 / 24$ \\
\hline 7 & $10.0 \mathrm{~mm}$ & 2 & 2 & $\begin{array}{c}\text { Serial section } \\
\text { in all } 2 \text { blks: } 2 \\
\text { SLNs+ }\end{array}$ & $\begin{array}{c}\text { BlkA: S2-6, } \\
\text { BlkB: S8 } \\
\text { onwards (42 } \\
\text { levels) }\end{array}$ & Positive & 15 & $\begin{array}{l}\text { Positive } \\
\text { in } 2 / 15\end{array}$ & $\begin{array}{l}\text { SLN: } 1.0 \\
\mathrm{~mm}\end{array}$ & $4 / 17$ \\
\hline 8 & $20.0 \mathrm{~mm}$ & 1 & 3 & None in SLN & None & Negative & 11 & $\begin{array}{c}\text { Positive } \\
\text { in } 1 \text { of } \\
11\end{array}$ & $\begin{array}{l}\text { Non-SLN: } \\
1.0 \mathrm{~mm}\end{array}$ & $1 / 12$ \\
\hline 9 & $20.0 \mathrm{~mm}$ & 1 & 3 & None in SLN & None & Negative & 12 & $\begin{array}{c}\text { Positive } \\
\text { in } 1 \text { of } \\
12\end{array}$ & $\begin{array}{l}\text { Non-SLN: } \\
12.0 \mathrm{~mm}\end{array}$ & $1 / 13$ \\
\hline 10 & $55.0 \mathrm{~mm}$ & 3 & 5 & None in SLN & None & Negative & 10 & $\begin{array}{c}\text { Positive } \\
\text { in } 1 \text { of } \\
10\end{array}$ & $\begin{array}{l}\text { Non-SLN: } \\
5.0 \mathrm{~mm}\end{array}$ & $1 / 13$ \\
\hline
\end{tabular}


had tumour in both SLNs and axillary lymph nodes. Additionally, there were three cases $(30 \%)$ of axillary nodal metastases where no tumour was found in all thinly sliced tissue blocks of SLNs despite serial levelling and IHC validation. These were classified as a false-negative SLN examination result. The metastatic tumours found in axillary nodes of these 3 false-negative cases varied between 1 to $10 \mathrm{~mm}$ in diameter (both micro- and macrometastases). Table 2 summarizes the sentinel and axillary lymph nodes status for all 24 cases of clinically node-negative breast carcinomas.

Characteristics of the 10 cases of node-positive breast carcinoma patients are summarized in Table 3. Tumours found in the nodes varied between ITC to a size of 12.0 $\mathrm{mm}$ in diameter. Between one to 11 nodes were involved in each patient. The primary breast tumour size of nodepositive patients varied between 10.0 to $35.0 \mathrm{~mm}$ with a mean of $26.0 \mathrm{~mm}$. Mean tumour size of node-negative tumours was $25.6 \mathrm{~mm}$. There was no significant difference between tumour size of node-positive and node-negative patients.

\section{Discussion}

Previous authors have reported a correlation between primary tumour size and risk for axillary node metastases (Chu et al., 1999; Kamath et al., 2001; Madsen et al., 2013). Although Madsen and co-workers (2013) found a linear relationship between tumour size and occurrence of lymph node metastases our study did not demonstrate a significant difference in primary tumour size between patients with or without nodal metastases. This may be due to the small number of cases in our pilot study. Tumour size, however, should not be the determinant in selecting patients to undergo SLN biopsy (Amoui et al., 2012; Fancellu et al., 2012). SLN biopsy could be performed for clinically node-negative breast carcinomas with primary tumours up to $5 \mathrm{~cm}$ in diameter; bearing in mind that larger tumours have a higher risk of having positive sentinel nodes (Fancellu et al., 2012). Also, larger tumours $>5 \mathrm{~cm}$ in size, burdened with a higher risk of axillary tumours, were associated with a lower identification rate of SLNs (Wong et al., 2001a; Straver et al., 2010). SLN biopsy could also be used for breast cancer patients treated with neoadjuvant chemotherapy with acceptable false negative rate (Koslow et al., 2014 ).

Sentinel lymph nodes had been demonstrated to have the highest risk for containing metastatic disease (Giuliano et al., 1994), thus it would be logical to evaluate them closely. In cases where SLNs were negative for tumour, it has previously been reported that the probability of subsequent non-SLNs containing tumour was very low (12\%)(Albertini et al., 1996; Reintgen et al., 1998; Dauway et al., 1999). Several other investigators demonstrated that SLNs were the only site of disease with an incidence of 25-60\% (Giuliano et al., 1994; Veronesi et al., 1997; Barnwell et al., 1998; Kamath et al., 2001). Similarly we reported $50 \%$ of patients with tumour only in SLNs when the nodes were involved and $70 \%$ of our patients with metastatic nodes had tumour in the SLNs.

Patients in our study had an average of 1.9 sentinel nodes harvested by combined technetium radiotracer and blue dye; similar to results from other authors (between 1.8 to 2.0 SLNs) (Albertini et al., 1996; Dauway et al., 1999; Gill et al., 2011). On the other hand, in practice a larger number of axillary nodes (between 15 to 30) are excised (Pendas et al., 2000). In our study, between 9 to 23 axillary lymph nodes were excised per patient. Detailed examination of all axillary nodes may thus be impossible owing to time constraints and workload of laboratories and pathologists. However, it may be possible to examine sentinel nodes more closely than current routine practice. Traditionally one initial H\&E section from each block of a node isolated was performed and screened (Verma et al., 2014). The nodes removed would, at most, be halved if they were large but not thinly sliced. It has previously been reported that this routine staining practice could miss up to $33 \%$ of metastases (Dowlatshahi et al., 1997). Currently, there is no consensus or standard protocol for examining SLNs and there are variations in processing and histopathological examination of SLNs between hospitals and institutions (Verma et al., 2014).

Thinly-sliced tissue from SLNs could improve detection of nodal disease (Weaver, 2010). Our study showed that more patients were upstaged to node-positive by examining only the initial H\&E sections of these thinlysliced tissue blocks of SLNs. The single most important fundamental recommendation in ensuring proper breast staging and pathological assessment of sentinel nodes would be to thinly slice the sentinel nodes prior to embedding. This would improve the likelihood of detecting macrometastatic tumours. Lee et al. (2000) reported that the recommendation by the National Coordinating Group for Breast Screening Pathology (1997) to take up to 4 separate blocks from each node depending on size; could apply for assessment of sentinel nodes in most hospitals. The latest sentinel node guidelines from United Kingdom (Ellis, 2005) recommended slicing nodes more than $5 \mathrm{~mm}$ in diameter at intervals of approximately $3 \mathrm{~mm}$ or less as an alternative to performing serial or step sectioning. Similarly, the College of American Pathologists and the American Society of Clinical Oncology (Fitzgibbons et al., 2000; Lyman et al., 2005) recommended careful attention when slicing SLNs and keeping the thickness to less than $2.0 \mathrm{~mm}$. Both approaches advocated screening of a single $\mathrm{H} \& \mathrm{E}$ section from thin blocks to detect macrometastases and therefore reducing unnecessary workload to perform additional serial or step sectioning. However, slicing sentinel nodes to 2 or $3 \mathrm{~mm}$ thickness is an approximate event, and dependent on staff skillset. If performed properly, most macrometastases will be detected. We were not able to consistently slice nodes to 2 or $3 \mathrm{~mm}$ thickness with a free hand and therefore compromised by slicing them to no more than $5 \mathrm{~mm}$ thickness, estimated between 3 to $5 \mathrm{~mm}$.

With our method of SLN examination, $71.4 \%$ of metastases were found at initial sections of the thinly sliced tissue blocks but very few additional cases were found after serial sectioning for a further $0.2 \mathrm{~mm}$ thickness. In the two cases found by detailed examination (serial sectioning), there was only low volume of tumour (micrometastases or ITC) present. Kamath and co-workers 
(2001) found that the standard examination of sentinel lymph nodes would have missed $26 \%$ of patients with metastatic disease in regional nodes. This was similarly reported by other authors (Cserni et al., 2004; Groen et al., 2007; Grabau et al., 2011).

Alternatively, step sectioning or multi sectioning approaches have been proposed, where 4-5 levels were taken 200-250 microns apart and stained with H\&E (Grabau et al., 2011; Ensani et al., 2013). This allowed each paraffin block to be cut to a further depth of $1 \mathrm{~mm}$. Some authors (Torrenga et al., 2001; Grabau et al., 2011; Ensani et al., 2013) demonstrated significantly increased detection rate of tumour metastases with this method over single sectioning while other authors (Dowlatshahi et al., 1997; Freneaux et al., 2002) showed no significant difference. This method requires more time and training to execute and may not be applicable in many laboratories. Most of the tumours detected either by serial or step section were micrometastases or ITC. There has been differing reports of the outcome of patients with micrometastases or ITC in SLNs compared to node-negative patients. Some recent studies showed a worse outcome (Weaver et al., 2000; de Boer et al., 2010; Andersson et al., 2010; Patani and Mokbel, 2011) while others show no difference in survival (Huvos et al., 1971; Gobardhan et al., 2009). The clinical significance of detecting micrometastases in light of the current evidence remains uncertain and thus the increased amount of workload, time and cost to proceed with serial or step-sectioning routinely may not be justified.

Weaver et al. (2002) and Amir et al. (2012) reported that only 4.4 to $6.4 \%$ of occult metastases found in negative sentinel nodes by immunohistochemical validation were not detected by $\mathrm{H} \& \mathrm{E}$ staining. Ensani et al. (2013) found that there was no difference between step sectioning and IHC staining if ITC were excluded as IHC staining only increased detection of ITC. These tumours may not have any additional significance in recurrence or disease-free survival of the patients as they were mainly isolated tumour cells (Amir et al., 2012). The additional resources needed to perform IHC as a routine on deeper sections has not been justified (Ellis, 2005; Tai et al., 2011). We also were not able to detect any additional cases of metastases with IHC. However, IHC can be used to confirm suspicious tumours when required. Detecting micrometastases by serial sectioning and immunohistochemical validation was far more labourintensive with resultant poor yield and cannot be expected to be part of a standard protocol. However, thinly slicing blocks of 3 to $5 \mathrm{~mm}$ thickness could be recommended and much easily adopted into the routine practice.

Investigators reported between $0-30 \%$ false negative rates in different studies (Kamath et al., 2001; Veronesi et al., 2003; Lyman et al., 2005; Goyal et al., 2006; Kim et al., 2006). There are many factors that could contribute to the false negative rate for the sentinel node biopsy. Using only one of the two methods to identify the SLNs operatively may result in missing detection of the actual sentinel nodes. The combined use of blue dye and isotope in procuring the nodes (Cody et al., 1999; McMasters et al., 2000; Vijayakumar et al., 2005; Goyal et al., 2006) would improve the false negative rate, as would the surgeon's level of experience with the sentinel node biopsy technique (Cody et al., 1999; Liberman, 2000; Vijayakumar et al., 2005; Abdollahi et al., 2010). Although a combined blue-dye and radiotracer technique was used, we still had a high false negative rate of $30 \%$. As this was the first experience in conducting sentinel lymph node biopsies for our multi-disciplinary team, the associated learning curve may have contributed to this false-negative rate. Surgical skill, injection procedures and the technique of processing the nodes could also all contribute to this. It was thus advised by previous authors (Straver et al., 2010; Amoui et al., 2012) that the entire team complete between $20-40$ procedures and meet the criteria of obtaining less than $10 \%$ false negative rates and identifying more than $90 \%$ of SLNs before a satisfactory result could be expected.

The false negative rate of SLN biopsy was significantly decreased when more than one SLN was excised (Tafra et al., 2001; Wong et al., 2001b; Martin et al., 2005; Goyal et al., 2006; Krag et al., 2007; Zakaria et al., 2007; Gill et al., 2011). It has been demonstrated that the false negative rate was three times higher where only one SLN was excised, as compared to when more than one was excised (Wong et al., 2001b; Martin et al., 2005; Goyal et al., 2006; Krag et al., 2007). Some researchers recommended up to four excised SLNs to increase the diagnostic yield and reduce the false negative rate (Zakaria et al., 2007; Gill et al., 2011). In two of our three false negative cases there was only one SLN removed per case. Our third case had 3 sentinel nodes removed but showed no tumour despite levelling.

Tumour metastases may be missed as tissue blocks were never routinely sectioned to exhaustion. This could contribute to the false negative rate. In one study, Andersson et al. (2013) found a further $18 \%$ of previously undiagnosed tumour metastases in their false negative group when they performed step sectioning until the blocks were exhausted. False negative SLN biopsy may also be the result of an axillary skip metastasis where the cancer cells "skipped" pass the SLNs and spread to other non-sentinel nodes in the axillary basin due to variation in lymphatic drainage (Keskek et al., 2006; Sun et al., 2012).

Conclusions and Recommendations: Sentinel lymph node biopsy can be performed in hospitals with a multidisciplinary team that have the expertise and are equipped to procure SLNs and perform adequate histopathological examination. It is important to recommend a single feasible pathological protocol for examination of sentinel nodes for breast cancer patients that can be applied to most hospitals without compromising on detection of macrometastases but taking into consideration the technical support of the laboratory and cost-effectiveness of the procedure. This would include thin slicing of the sentinel nodes to between 3 to $5 \mathrm{~mm}$ thickness before embedding. Our study showed that all SLN macrometastases can be detected by this method. Serial or step sectioning of the individual blocks may increase the probability of detecting micrometastases or isolated tumour cells but was far too labour-intensive and impractical in routine busy laboratories. IHC may be used when there were any suspicious findings but not 
routinely. The false negative rate could be further reduced with improved experience of the entire multidisciplinary team and ensuring procurement of more than one SLNs, using combination of radiotracer and blue-dye.

\section{Acknowledgements}

We would like to record a note of appreciation to Dr. Nik Ros Mazeni binti Yusoff, Head of Department of Pathology and Dr. Noraida Khalid, Head of Unit of Histopathology for their guidance and permission for this study, Miss Nur Hanani Ahmad Nakaruddin and Miss Norsalehah W Abdulla (scientific officers) for their tireless assistance and contribution to this study.

\section{References}

Abdollahi A, Jangjoo A, Dabbagh Kakhki VR, et al (2010). Factors affecting sentinel lymph node detection failure in breast cancer patients using intradermal injection of the tracer. Rev Esp Med Nucl, 29, 73-7.

Albertini JJ, Lyman GH, Cox C, et al (1996). Lymphatic mapping and sentinel node biopsy in the patient with breast cancer. JAMA, 276, 1818-22.

Amir AS, Azar FP, Sahram N, et al (2012). Prevalence of occult metastases in axillary sentinel lymph nodes of breast carcinoma. Pol J Pathol, 63, 40-4.

Amoui M, Akbari ME, Tajeddini A, et al (2012). Value of sentinel lymph node biopsy in breast cancer surgery with simple pathology facilities--an Iranian local experience with a review of potential causes of false negative results. Asian Pac J Cancer Prev, 13, 5385-9.

Andersson Y, Frisell J, Sylvan M, et al (2013). Causes of falsenegative sentinel node biopsy in patients with breast cancer. Br J Surg, 100, 775-83.

Andersson Y, Frisell J, Sylvan M, et al ( 2010). Breast cancer survival in relation to the metastatic tumor burden in axillary lymph nodes. J Clin Oncol, 28, 2868-73.

Barnwell JM, Arredondo MA, Kollmorgen D, et al (1998). Sentinel node biopsy in breast cancer. Ann Surg Oncol, 5, 126-30.

Borgstein PJ, Pijpers R, Comans EF, et al (1998). Sentinel lymph node biopsy in breast cancer: guidelines and pitfalls of lymphoscintigraphy and gamma probe detection. $\mathrm{J} \mathrm{Am}$ Coll Surg, 186, 275-83.

Chagpar A, Pilavas J, Chao C, et al (2003). Sentinel lymph node biopsy for breast cancer:addressing the controversies. Cancer Therapy, 1, 223-32.

Chu KU, Turner RR, Hansen NM, et al (1999). Do all patients with sentinel node metastasis from breast carcinoma need complete axillary node dissection? Ann Surg, 229, 536-41.

Cody HSr, Hill AD, Tran KN, et al (1999). Credentialing for breast lymphatic mapping: how many cases are enough? Ann Surg, 229, 723-6.

Cox CE, Bass SS, McCann CR, et al (2000). Lymphatic mapping and sentinel lymph node biopsy in patients with breast cancer. Annu Rev Med, 51, 525-42.

Cserni G (1999). Metastases in axillary sentinel lymph nodes in breast cancer as detected by intensive histopathological work up. J Clin Pathol, 52, 922-4.

Cserni G, Gregori D, Merletti F, et al (2004). Meta-analysis of non-sentinel node metastases associated with micrometastatic sentinel nodes in breast cancer. Br J Surg, 91, 1245-52.

Dauway EL, Giuliano R, Haddad F, et al (1999). Lymphatic mapping in breast cancer. Hematol Oncol Clin North Am,
13, 349-71.

de Boer M, van Dijck JA, Bult P, et al (2010). Breast cancer prognosis and occult lymph node metastases, isolated tumour cells and micrometastases. J Natl Cancer Inst, 102, 410-25.

Dowlatshahi K, Fan M, Snider HC, et al (1997). Lymph node micrometastases from breast carcinoma: reviewing the dilemma. Cancer, 80, 1188-97.

Ellis IO (2005). Pathology reporting of breast disease. In 'NHS Breast Screening Programme (NHSBSP) publication. NHS Cancer Screening Programmes and The Royal College of Pathologists.', Eds Publication No.58. London,

Ensani F, Enayati L, Rajabiani A, et al (2013). Improved detection of metastases by step sectioning and immunohistochemical staining of axillary sentinel nodes in patients with breast carcinoma. Asian Pac J Cancer Prev, 14, 5731-4.

Fancellu A, Cottu P, Feo CF, et al (2012). Sentinel node biopsy in early breast cancer: lessons learned from more than 1000 cases at a single institution. Tumori, 98, 413-20.

Fitzgibbons PL, Page DL, Weaver D, et al (2000). Prognostic factors in breast cancer. College of American Pathologists Consensus Statement 1999. Arch Pathol Lab Med, 124, 966-78.

Fréneaux P, Nos C, Vincent-Salomon A, et al (2002). Histological detection of minimal metastatic involvement in axillary sentinel nodes: a rational basis for a sensitive methodology usable in daily practice. Mod Pathol, 15, 641-6.

Gill J, Lovegrove R, Naessens K, et al (2011). Sentinel lymph node biopsy in breast cancer: an analysis of the maximum number of nodes requiring excision. Breast $J, 17,3-8$.

Giuliano AE, Dale PS, Turner RR, et al (1995). Improved axillary staging of breast cancer with sentinel lymphadenectomy. Ann Surg, 222, 394-401.

Giuliano AE, Jones RC, Brennan M, et al (1997). Sentinel lymphadenectomy in breast cancer. J Clin Oncol, 15, 2345-50.

Giuliano AE, Kirgan DM, Guenther JM, et al (1994). Lymphatic mapping and sentinel lymphadenectomy for breast cancer. Ann Surg, 220, 391-401.

Gobardhan PD, Elias SG, Madsen EV, et al (2009). Prognostic value of micrometastases in sentinel lymph nodes of patients with breast carcinoma: a cohort study. Ann Oncol, 20, 41-8.

Goyal A, Newcombe RG, Chhabra A, et al (2006). Factors affecting failed localisation and false-negative rates of sentinel node biopsy in breast cancer--results of the ALMANAC validation phase. Breast Cancer Res Treat, 99, 203-8.

Grabau D, Ryden L, Fernö M, et al (2011). Analysis of sentinel node biopsy - a single-institution experience supporting the use of serial sectioning and immunohistochemistry for detection of micrometastases by comparing four different histopathological laboratory protocols. Histopathol, $\mathbf{5 9}$, 129-38.

Groen RS, Oosterhuis AW, Boers JE (2007). Pathologic examination of sentinel lymph nodes in breast cancer by a single haematoxylin-eosin slide versus serial sectioning and immunocytokeratin staining: clinical implications. Breast Cancer Res Treat, 105, 1-5.

Huvos A, Hutter R, Berg J (1971). Significance of axillary macrometastases and micrometastases in mammary cancer. Ann Surg, 173, 44-6.

Jakub JW, Pendas S, Reintgen DS (2003). Current status of sentinel lymph node mapping and biopsy: facts and controversies. Oncologist, 8, 59-68.

Jannink I, Fan M, Nagy S, et al (1998). Serial sectioning of sentinel nodes in patients with breast cancer: a pilot study. Ann Surg Oncol, 5, 310-4.

Kamath VJ, Giuliano R, Dauway EL, et al (2001). Characteristics 
of the sentinel lymph node in breast cancer predict further involvement of higher-echelon nodes in the Axilla. Arch Surg, 136, 688-92.

Keskek M, Balas S, Gokoz A, et al (2006). Re-evaluation of axillary skip metastases in the era of sentinel lymph node biopsy in breast cancer. Surg Today, 36, 1047-52.

Kim T, Giuliano AE, Lyman GH (2006). Lymphatic mapping and sentinel lymph node biopsy in early-stage breast carcinoma: a metaanalysis. Cancer, 106, 4-16.

Koslow SB, Eisenberg RE, Qiu Q, et al (2014). Sentinel lymph node biopsy is a reliable method for lymph node evaluation in neoadjuvant chemotherapy-treated patients with breast cancer. Am Surg, 80, 171-7.

Krag D, Weaver D, Ashikaga T, et al (1998). The sentinel node in breast cancer--a multicenter validation study. $N$ Engl $J$ Med, 339, 941-6.

Krag DN, Anderson SJ, Julian TB, et al (2007). Technical outcomes of sentinel-lymph-node resection and conventional axillary-lymph-node dissection in patients with clinically node-negative breast cancer: results from the NSABP B-32 randomised phase III trial. Lancet Oncol, 8, 881-8.

Lee AHS, Ellis IO, Pinder SE, et al (2000). Pathological assessment of sentinel lymph-node biopsies in patients with breast cancer. Virchows Arch, 436, 97-101.

Liberman L (2000). Pathologic analysis of sentinel lymph nodes in breast carcinoma. Cancer, 88, 971-7.

Lin PP, Allison DC, Wainstock J, et al (1993). Impact of axillary lymph node dissection on the therapy of breast cancer patients. J Clin Oncol, 11, 1536-44.

Lyman GH, Giuliano AE, Somerfield MR, et al (2005). American Society of Clinical Oncology guideline recommendations for sentinel lymph node biopsy in early-stage breast cancer. $J$ Clin Oncol, 23, 7703-20.

Madsen EV, Elias SG, van Dalen T, et al (2013). Predictive factors of isolated tumor cells and micrometastases in axillary lymph nodes in breast cancer. Breast, 22, 748-52.

Martin RC, Chagpar A, Scoggins CR, et al (2005). Clinicopathologic factors associated with false-negative sentinel lymph-node biopsy in breast cancer. Ann Surg, 241, 1005-12.

McMasters KM, Tuttle TM, Carlson DJ, et al (2000). Sentinel lymph node biopsy for breast cancer: a suitable alternative to routine axillary dissection in multi-institutional practice when optimal technique is used. J Clin Oncol, 18, 2560-6.

National.Coordinating.Group.for.Breast.Screening.Pathology 1997. Pathology reporting in breast cancer screening, Sheffield:NHSBSP Publications.

Patani N, Mokbel K (2011). Clinical significance of sentinel lymph node isolated tumour cells in breast cancer. Breast Cancer Res Treat, 127, 325-34.

Pendas S, Dauway EL, Giuliani R, et al (2000). Sentinel node biopsy in ductal carcinoma in situ patients. Ann Surg Oncol, 7, 15-20.

Reintgen DS, Haddad F, Pendas S, et al (1998). Lymphatic mapping and sentinel lymph node biopsy. Sci Am, 17, 1-17.

Snider H, Dowlatshahi K, Fan M, et al (1999). Sentinel node biopsy in staging of breast cancer. Am J Surg, 176, 305-10.

Straver ME, Meijnen P, van Tienhoven G, et al (2010). Sentinel node identification rate and nodal involvement in the EORTC 10981-22023 AMAROS trial. Ann Surg Oncol, 17, 1854-61.

Sun J, Yin J, Ning L, et al (2012). Clinicopathological characteristics of breast cancers with axillary skip metastases. J Invest Surg, 25, 33-6.

Tafra L, Lannin DR, Swanson MS, et al (2001). Multicenter trial of sentinel node biopsy for breast cancer using both technetium sulfur colloid and isosulfan blue dye. Ann Surg, 233, 51-9.
Tai P, Joseph KJ, Yu E (2011). Issues related to sentinel lymph node assessment in the management of breast cancer-what are relevant in pathology reports? Patholog Res Int, 2011.

Torrenga H, Rahusen FD, Meijer S, et al (2001). Sentinel node investigation in breast cancer; detailed analysis of the yield from step sectioning and immunohistochemistry. J Clin Pathol, 54, 550-2.

Turner RR, Ollila DW, Krasne DL, et al (1997). Histopathologic validation of the sentinel lymph node hypothesis for breast carcinoma. Ann Surg, 226, 271-8.

Turner RR, Ollila DW, Stern S, et al (1999). Optimal histopathologic examination of the sentinel lymph node for breast carcinoma staging. Am J Surg Pathol, 23, 263-7.

van Diest PJ (1999). Histopathological workup of sentinel lymph nodes: how much is enough? J Clin Pathol, 52, 871-3.

van Diest PJ, Peterse HL, Borgstein PJ, et al (1999). Pathological investigation of sentinel lymph nodes. Eur J Nucl Med, 26, 43-9.

Verma R, Rajan SS, Verghese ET, et al (2014). Pathological evaluation of the staging axillary lymph nodes for breast cancer: a national survey in the United Kingdom. Histopathol, 65, 707-11.

Veronesi U, Paganelli G, Galimberti V, et al (1997). Sentinelnode biopsy to avoid axillary dissection in breast cancer with clinically negative lymph-nodes. Lancet, 349, 1864-7.

Veronesi U, Paganelli G, Viale G, et al (1999). Sentinel lymph node biopsy and axillary dissection in breast cancer: results in a large series. J Natl Cancer Inst, 91, 368-73.

Veronesi U, Paganelli G, Viale G, et al (2003). A randomized comparison of sentinel-node biopsy with routine axillary dissection in breast cancer. $N$ Engl J Med, 349, 546-53.

Vijayakumar V, Boerner PS, Jani AB, et al (2005). A critical review of variables affecting the accuracy and false-negative rate of sentinel node biopsy procedures in early breast cancer. Nucl Med Commun, 26, 395-405.

Weaver D, Krag DN, Manna EA, et al (2002). Comparison of occult micrometastasis detection in breast caner sentinel lymph nodes using manual cytokeratin immunohistochemistry and image analysis. Mod Pathol, 15, 55A-6A.

Weaver DL (2010). Pathology evaluation of sentinel lymph nodes in breast cancer: protocol recommendations and rationale. Mod Pathol, 23, 26-32.

Weaver DL, Krag DN, Ashikaga T, et al (2000). Pathologic analysis of sentinel and nonsentinel lymph nodes in breast carcinoma: a multicenter study. Cancer, 88, 1099-107.

Wilking N, Rutqvist LE, Carstensen J, et al (1992). Prognostic significance of axillary nodal status in primary breast cancer in relation to the number of resected nodes. Stockholm Breast Cancer Study Group. Acta Oncol, 31, 29-35.

Wong SL, Edwards MJ, Chao C, et al (2001a). The effect of lymphatic tumor burden on sentinel lymph node biopsy results. Breast J, 8, 192-8.

Wong SL, Edwards MJ, Chao C, et al (2001b). Sentinel lymph node biopsy for breast cancer: impact of the number of sentinel nodes removed on the false-negative rate. $J \mathrm{Am}$ Coll Surg, 192, 684-9.

Zakaria S, Degnim AC, Kleer CG, et al (2007). Sentinel lymph node biopsy for breast cancer: how many nodes are enough? J Surg Oncol, 96, 554-9. 